\title{
$\mathrm{TCOM}$ \\ Introduction to "Specialised portals, online information services, scholarly online networks: the impact of e-infrastructures on science communication and scholarly community building"
}

\section{Dirk Hommrich}

Abstract

Keywords

DOI
While most researchers still primarily use emails and simple websites for professional communication, the number of specialised online portals, information services and scholarly social online networks is constantly growing. This development led to the $6^{\text {th }}$ workshop organized by the team of openTA, an online portal for technology assessment. This issue of JCOM pools commentaries on the workshop which deal with questions such as: what are the criteria of successful digital infrastructures? Which potential for changing workflows or scholarly interaction and collaboration patterns do we ascribe to digital infrastructures?

Scholarly communication; Science and media

https://doi.org/10.22323/2.17020301

Intellectual exchange among researchers, the working methods of academics as well as internal communication in scientific communities are increasingly based on the use of multifunctional and interactive online media [Lüthje, 2014; Schäfer, Kristiansen and Bonfadelli, 2015, pp. 24-26]. Amid the rapid transformation of public and popular science specialised portals, specialised information services and scholarly online networks are three variants of virtual research environments that provide such multifunctional services for science communication as well as scholarly communication. On 16-17 November 2017 the $6^{\text {th }}$ openTA workshop explored the technical, organisational, business and social dimensions of "cyberscience" [Nentwich, 2003; Nentwich and König, 2012; Leggewie and Mühlleitner, 2007, pp. 57-62]. ${ }^{1}$

The workshop offered a forum to discuss and exchange ideas about communication, cooperation and collaboration in the upcoming era of so-called

\footnotetext{
1 "OpenTA" is a project by the Institute for Systems Analysis and Technology Assessment at the Karlsruhe Institute of Technology (KIT) and FIZ Karlsruhe - Leibniz Institute for Information Infrastructure. OpenTA is funded by the German Research Foundation (DFG) in order to build an online portal for the (German-speaking) scientific community of technology assessment: for the prehistory since 2006, the concept and non-commercial aim of openTA see Hommrich et al. [2018, pp. 251-255].
} 
"Open Science" [cf. Riehm and Nentwich, 2017]. Since there is a need to know more about lessons learned and best practice, the workshop aimed at gaining insights into practice- and problem-oriented case examples from different scientific disciplines and research areas in order to make them a common subject of interdisciplinary learning about infrastructure work and community building in science. The workshop was a gathering of operators of scholarly online systems (SOS), researchers working in the field, as well as science bloggers, science communicators and the scientific community interested in internet-based scientific e-infrastructures and their effects. ${ }^{2}$

Alongside many practical topics, the workshop's debates focused on terminological issues, in particular the clarification of its key concepts, which were seen as prerequisite to answering questions concerning the possible impact of SOS on scientific community building. The three central concepts of the 6th workshop by openTA can be put as follows:

1. Specialised (online) information services ("Fachinformationsdienste", FID) follow a library-oriented purpose; they especially try to cover the peak demand for scientific publications (and further content) according to the needs of special scientific communities. ${ }^{3}$

2. Specialised portals ("Fachportale") can be defined as web applications and services which combine and integrate different subject-specific and scientific functions and content from heterogeneous sources.

3. Scholarly online networks ("Wissenschaftsnetzwerke") highlight personal members who represent themselves and their work and who establish communicative connections to other members of the network. ${ }^{4}$

These key concepts of SOS attempt to cover the contemporary field of web-based information and communication systems for scientific and scholarly work [Riehm and Hommrich, 2018]. However, while they share the implicit aim of elevating e-infrastructures from an instrument to a "partner" in scientific workflows, the three concepts are used in confusing and inconsistent ways; sometimes "platform", 5 "gate" or "site" are being used instead, and most empirical examples feature hybrid forms of SOS.

\footnotetext{
${ }^{2}$ Of course, there are traditional ways to telecommunicate by voice via telephone or radio (also digitalised by now). Since these options were not discussed in the workshop, this set of commentaries concentrates on written, i.e., textual, information and communication by means of screens and displays of online media.

${ }^{3}$ The official funding programme "Information on the Specialised Information Services Programme" of the German Research Foundation (DFG) is available online at http://www.dfg.de/en/research_funding/programmes/infrastructure/lis/funding_ opportunities/informationservice_science/index.html, last visited on 26 January 2018.

${ }^{4}$ For a definition of social network sites see Ellison and Boyd [2013, p. 158, emphasis in original]: "A social network site is a networked communication platform in which participants 1) have uniquely identifiable profiles that consist of user-supplied content, content provided by other users, and/or system-provided data; 2 ) can publicly articulate connections that can be viewed and traversed by others; and 3) can consume, produce, and/or interact with streams of user-generated content provided by their connections on the site."

${ }^{5}$ According to Gillespie [2017], the expression "platform" has several problematic implications; the metaphor "downplays the fact that these services are not flat", it "obscures the fact that platforms are populated by many, diverse, sometimes overlapping, and sometime contentious communities" and the term "also helps elide questions about platforms' responsibility for their public footprint."
} 
The $6^{\text {th }}$ openTA workshop raised more questions than answers and although internet research is a growing field of interdisciplinary study, the participants agreed that there is an elementary need for continuing and deepening our knowledge on SOS. Therefore, before introducing the contributions of this set of commentaries, let me just note a few observations about topics which were mentioned at the workshop but not discussed in-depth:

- First and foremost the importance and influence of committers (promoters, innovators, contributors) who support a scientific community and its digital infrastructure voluntarily and free of charge became blatantly obvious, especially with non-commercial projects. Without such people, many SOS would be facing difficulties to keep their (non-profit) systems running.

- Perhaps usage studies, needs assessments and evaluation methods got the short end of the stick. Is it reasonable that those who run and manage a system also perform usage studies (bias instead of neutrality!)? How difficult is it to assess requirements, are there examples? How do we define and measure success?

- Business models are of great importance, all the more when project-linked funding and New Public Management belong to the political and economic conditions of science communication in general [Taubert, 2017; cf. Metag and Schäfer, 2017]

- Fostering a unique profile for a system while embracing (disciplinary, interdisciplinary, transdisciplinary) epistemic and social heterogeneity is a continuous and unresolved challenge of SOS.

In this issue of JCOM we present four commentaries on the impacts of specialised portals, online information services and scholarly (social) online networks on science communication and scholarly community building. Three of them are based on presentations at the workshop.

You can read an insightful contribution by Niels Taubert about his extensive research on scientific e-infrastructures (of which SOS are an integral part). In his text he investigates the conditions of the system "arXive" within the scientific community of international astronomy. The author describes central motifs of astronomers for using this digital infrastructure (which, by the way, is also used by the scientific community of physics) at different stages of their workflow.

Particularly early self-archiving of manuscripts by using repositories and the use of pre-prints in the astronomical community are practices which complement and change scholarly communication and which introduce new ways of feedback amongst researchers. Taubert concludes that a strong and well-organised community admittedly makes it more likely for a digital infrastructure to succeed but that a communitarian spirit and a lively scientific culture are not necessary for digitally enhanced research to work.

The second contribution by Johann Schaible, Sonja Strunk and David Brodesser describes an advanced example of how the German library system is transformed by digital infrastructures and information services. Their commentary on the "Fachinformationsdienst Soziologie" (FID Sociology or "SocioHub") can be read as 
an illuminating report which shows the progress of efforts to increase accessibility, visibility and sustainability in German sociology. Most German FIDs do not focus on collaboration by scientists. But the authors who are involved in the development of this online information service remarkably indicate that their SocioHub (that is to be launched in April 2018) is also designed as an academic "collaboration platform". Schaible and his colleagues give an estimation of how sociologists could use FID Sociology to reorganise collaboration and communication methods.

The third commentary, my own, first gives a synopsis of the central characteristics of those nine digital infrastructures which were subjects of the $6^{\text {th }}$ openTA workshop. It expounds a survey of German specialised portals and information services regarding their functions and features and outlines a possible typology for such SOS. Second, my contribution formulates some preliminary remarks on the putative effects of SOS. Particularly, my commentary calls into question if we really know enough about advanced and sophisticated forms of collaboration by means of such academic online services. Perhaps it is more appropriate to speak of a blind spot regarding our knowledge about SOS as a means of collaboration.

The final commentary by Ulrich Herb describes an attempt to develop an aggregation method for usage information from distributed open access repositories. Herb delineates the goals and problems the project "Open Access Statistics" had when they tried to measure impact in an alternative way. In this sense his commentary on the one hand can be read as a report about an early offspring of altmetrics and it is striking that some of the barriers the project faced were due to the more restrictive legal conditions of data mining in open access as opposed to commercial contexts. On the other hand, Herb's contribution may also be read as a commentary which argues that the reputation of SOS is essential for gaining users: "Critical for their success is the ability to raise the reputation of users. In other words, the impact of an e-infrastructure on science communication and scholarly community building depends largely on its own ability to provide impact." (Herb in this issue of JCOM)

Along these lines it will be illuminating to observe the development of the FID Sociology as collaboration tool and to keep track of the lessons learned from it within the field of SOS. The same holds true for both the astronomical scientific community's use of the pre-print repository "arXive" as it has been subject to Taubert's fieldwork and for Herb's appraisal of the political, legal and economic constraints of approaches to alternative metrics.

\section{References}

Ellison, N. B. and Boyd, D. M. (2013). Sociality Through Social Network Sites. Ed. by W. H. Dutton. Oxford, U.K.: Oxford University Press. https://doi.org/10.1093/oxfordhb/9780199589074.013.0008.

Gillespie, T. (2017). 'The Platform Metaphor, Revisited'. Institut für Internet und Gesellschaft. Berlin, Germany.

URL: https://www.hiig.de/en/blog/the-platform-metaphor-revisited/ (visited on 16th March 2018).

Hommrich, D., Pasucha, B., Razum, M. and Riehm, U. (2018). 'Normdaten und Datenanreicherung beim Fachportal openTA'. Der Bibliotheksdienst 52 (3-4), pp. 248-265. https://doi.org/10.1515/bd-2018-0031. 
Leggewie, C. and Mühlleitner, E. (2007). Die akademische Hintertreppe. Kleines Lexikon des wissenschaftlichen Kommunizierens. Frankfurt/Main, Germany: Campus Verlag.

Lüthje, C. (2014). 'Mediatisierte wissenschaftsinterne Kommunikation: Stand der Forschung und theoretische Rahmung'. kommunikation@gesellschaft 15 (special edition). URL: http://www. ssoar. info/ssoar/bitstream/handle/document/37 846/ssoar-ketg-2014-Luethje-Mediatisierte_wissenschaftsinterne_Komm unikation. pdf?sequence=3 (visited on 28th February 2018).

Metag, J. and Schäfer, M. S. (2017). 'Hochschulen zwischen Social Media-Spezialisten und Online-Verweigerern. Eine Analyse der Online-Kommunikation promotionsberechtigter Hochschulen in Deutschland, Österreich und der Schweiz'. Studies in Communication I Media 6 (2), pp. 160-195. https://doi.org/10.5771/2192-4007-2017-2-160.

Nentwich, M. (2003). Cyberscience. Vienna, Austria: Austrian Academy of Sciences Press. URL: http: //www . doabooks . org/doab? func=fulltext\&rid=15103 (visited on 3rd March 2018).

Nentwich, M. and König, R. (2012). Cyberscience 2.0. Research in the Age of Digital Social Networks. Frankfurt/Main, Germany: Campus Verlag.

Riehm, U. and Hommrich, D. (2018). 'Zur Einführung: Fachportale, Fachinformationsdienste, Wissenschaftsnetzwerke - Merkmale webbasierter, wissenschaftlicher Informations- und Kommunikationssysteme'. Der Bibliotheksdienst 52 (3-4), pp. 170-184. https://doi.org/10.1515/bd-2018-0025.

Riehm, U. and Nentwich, M. (2017). 'Open Science aus Perspektive der Technikfolgenabschätzung'. TATuP Zeitschrift für Technikfolgenabschätzung in Theorie und Praxis 26 (1-2), pp. 11-17. https://doi.org/10.14512/tatup.26.1-2.11.

Schäfer, M., Kristiansen, S. and Bonfadelli, H. (2015).

'Wissenschaftskommunikation im Wandel. Relevanz, Entwicklung und Herausforderungen des Forschungsfeldes'. In: Wissenschaftskommunikation im Wandel. Ed. by M. Schäfer, S. Kristiansen and H. Bonfadelli. Cologne, Germany: Herbert von Halem Verlag, pp. 10-42.

Taubert, N. (2017). 'Kommunitaristische und kommerzielle Trägerschaft digitaler Informationsinfrastruktur in der Wissenschaft'. die hochschule 26 (1), pp. 29-39.

Author

\section{How to cite}

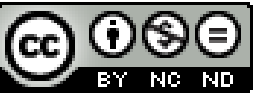

Dirk Hommrich is senior researcher at the Institute for Technology Assessment and Systems Analysis at the Karlsruhe Institute of Technology and board member of the Institute for the Study of Culture Heidelberg. He has been fellow of the postgraduate program "Topology of Technology" at TU Darmstadt and lecturer at the Faculty of Humanities and Social Sciences at the HSU, Hamburg, Germany. His publications focus on science communication and scholarly communication as well as on pop science and visual culture. E-mail: dirk.hommrich@kit.edu.

Hommrich, D. (2018). 'Introduction to "Specialised portals, online information services, scholarly online networks: the impact of e-infrastructures on science communication and scholarly community building"'. JCOM 17 (02), C01. https://doi.org/10.22323/2.17020301.

(C) The Author(s). This article is licensed under the terms of the Creative Commons Attribution - NonCommercial - NoDerivativeWorks 4.0 License. ISSN 1824-2049. Published by SISSA Medialab. jcom.sissa.it 